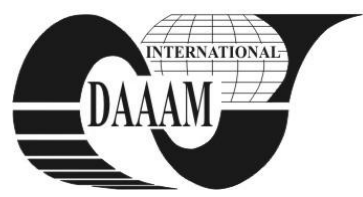

\title{
THE LEVEL OF LEADERSHIP IN THE APPLICATION OF QUALITY MANAGEMENT
}

\author{
MLKVA, M[iroslava]; PAULOVA, I[veta] \& RUSKOVA, D[agmar]
}

\begin{abstract}
Leadership is one of the key principles that affect the improvement and streamlining for the implementation of a quality management system. The paper deals with the survey of the leadership application as one of the principles of quality management in the Slovak Republic's organizations. The surveys were conducted through questionnaires and within it we investigated how are in practice carried out activities related to this principle.
\end{abstract}

Key words: quality management, leadership, process improve

\section{INTRODUCTION}

The current approach to a quality management system is based on principles that were specified on the basis of experience and good practices and approaches of major leaders in the field of quality management. Eight principles were defined that nowadays create the backbone of the implementation of a quality management system and are incorporated in the standards of ISO 9000:2005. The first principle is leadership.

Leadership leads managers to a fundamental approach that in turn lead to action, an example for others, understanding and flexible reactions to changes in their environment, the constant consideration of the needs of all concerned, including: customers, owners, suppliers, local communities and society as a whole. Their main task is to state the clear visions of an organisation's future, setting values and an ethical constellation of roles at all levels of an organization, to provide the staff with necessary resources and freedom of decision making for activities under their responsibility, to develop an open and decent communication, setting challenging goals and aspirations, using strategies to reach these aims. Executives promote the unity of purpose and direction of the organization. They have to create and maintain an internal environment in which workers could be fully involved in achieving organizational goals.

The basic finding of the key factors when considering the development of small and medium- sized Slovak organizations is the leadership of organizations (Zgodavová, 2002).

The whole standard ISO 9001:2008, especially processes related to the liability of management are dedicated to the position of leaders in a quality management system.

\section{AIM}

Within the solving of the research project "Perspectives of quality management development in coherence with requirements of the 'Slovak Republic' market," we dealt with the issues of quality management applications in various branches of industrial practice. Through the survey, we assessed the level of application of the fundamental principles on which are quality management systems are designed.

The survey we conducted, via a questionnaire, was attended by 124 organizations in Slovakia from enterprises of different sizes. During evaluating the data, we divided the organizations into four groups according to company size and then we surveyed whether they had introduced or certified the quality management system. The structure of surveyed enterprises according to size of the enterprises was as follows: $4 \%$ of micro enterprises, $19 \%$, small enterprises $30 \%$ middle enterprises and $47 \%$ large enterprises. Almost all surveyed enterprises had implemented and certified a quality management system, so when evaluating the data we did not use this criterion for the distribution of enterprises

\section{RESULTS AND DISCUSSION}

The survey questions were also designed to detect, how in practice one may implement the activities related with the principle of leadership. First we tried to figure out how that principle is understood and applied in business practice, in quality management and whether there are differences in its application in business practice, in organizations of various sizes. In this paper we present some results obtained from a survey of the issues to which the questionnaire was designed from the following questions:

1. How is the principle of leadership understood in your organization?

2. Has an investigation taken place regarding the organisation's mission, vision and values with respect to changes of the external environment?

3 . In your organization are the executives generally seen not just as authority but also as a pattern of attitudes and procedures?

When asked "How is the principle of leadership understood in your organization?" we have the following options for response (Figure 1):

a) key principle for quality management system,

b) the key principle for a functioning quality management system,

c) managers are an ideal model of behaviour for all employees,

d) important for the competitiveness of the organization,

e) important for the strategic direction,

f) significant for providing the right resources for individual processes.

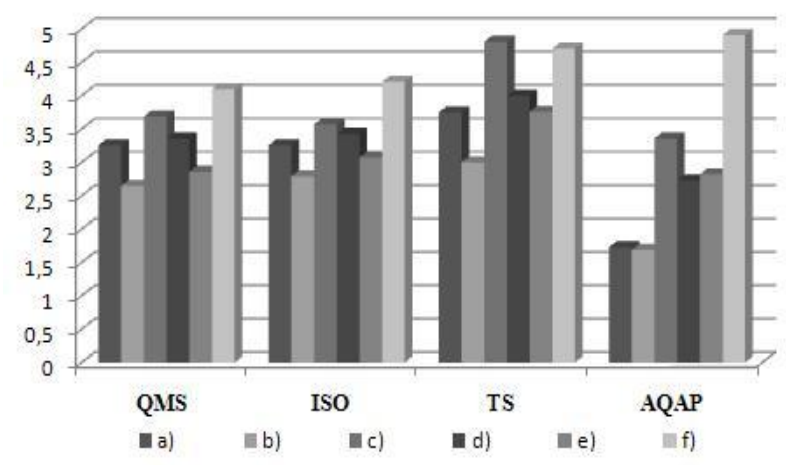

Fig. 1. Graphical representation of responses to question no 1 
When answering a given question, the respondents ranged individual possibilities according to the importance they attach to them. In evaluating this issue, we expressed the values in the table using the weighted average.

The results of the responses show that the principle of leadership in organizations, regardless of certification, is especially seen as a key principle for a functioning quality management system. When considering all the organizations, the second place in order of importance includes the option e) important for the strategic direction. The least important, respondents identified the option f) significant administrative resources to provide for individual processes.

Another issue we tried to determine whether the organization reviewed its mission, vision and values with respect to changes in the external environment (requirements of concerned sides, legislation, region, banks, foreign markets)? Respondents had the following options (Figure 2):
a) regularly
b) on the announced
d) not examined
or emerging changes
e) other
f) did not respond

c) randomly

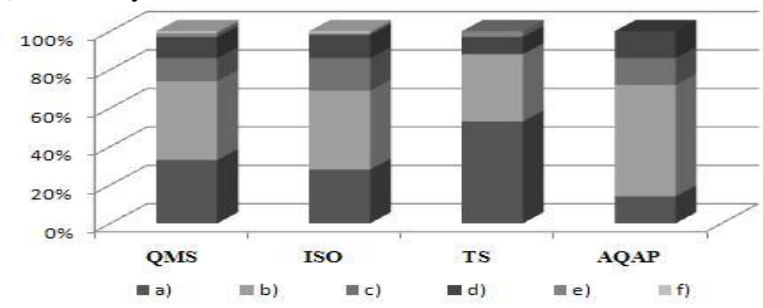

Fig. 2. Graphical representation of responses to question no. 2

As part of strategic management it is important to set out the future direction of the organization, articulate mission, vision and values to be followed in responding to them. From the answers to the question of the review mission, vision and values with regard to changes in environment, we can conclude that $33 \%$ of organizations do regularly review, $41 \%$ at the announced changes, $12 \%$ random and $11 \%$ does not do review.

When dividing a file according to an established quality management system, we found differences in the implementation of the review mission, vision and values with regard to changes of environment. The organisations with a TS 16949 certificate make regular reviews in 53\%, with ISO 9001 in $28 \%$ and with AQAP only in $14 \%$. It can be concluded that in organizations with the implementation of QMS according to TS 16949 standards dealing with a review mission, vision and values give greater attention than in the organizations with other type of QMS.

With the following question, we investigated whether in the organization the executives are in general seen not just as authority but also the ideal in the attitudes and actions. Possible answers were (Figure 3):
a) yes
c) mostly not
b) mostly yes
e) I cannot judge

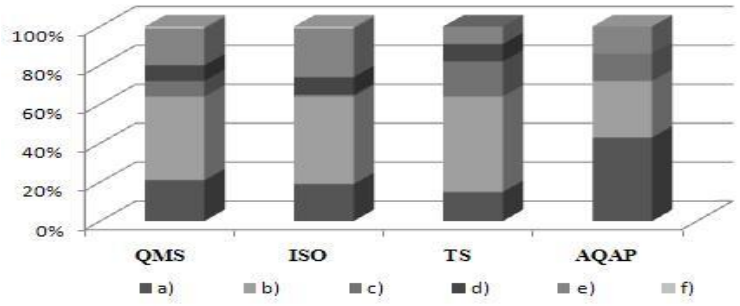

Fig. 3. Graphic representation of responses to question no. 3

The mission of manager is primarily to ensure the fulfilment of the objectives of the organization and to develop human potential in the organization. In fulfilling this mission it is important to be worthy for others to follow as an example and to motivate staff. When asked about the perception of managers in organizations in Slovakia with the established QMS system, we found that $64 \%$ of organizations are managers that are largely perceived as authoritative and a pattern in attitudes and behaviour, which is important in terms of meeting the principles of leadership.

In organizations with a system according to AQAP standards reflected this perception as the most evident when $43 \%$ of respondents chose answer a) and clearly answered "yes", managers are perceived as authoritative and an example in attitudes and behaviour. The answer no appears in this category $\mathrm{n}$ this category. The managers are perceived as an authority and an example.

\section{CONCLUSION}

Questionnaire survey, by which we tried to find out the level of applied principles of quality management in industrial practice within Slovakia. We obtained interesting results. We did not find striking differences between individual sectors, although in some areas their appeared smaller or larger differences in the applied principles of quality management. These differences, however, mostly result from the specific conditions of the particular industry.

The best level of applying the principles of quality management was in the automotive industry, which logically follows from the stricter requirements, as stated in the technical specification of TS 16949.Managers in organizations must deal with the new role of leader as an example of behaviour in attitudes and values. As the survey has shown, the principle of leadership in all types of organizations is mainly seen as a key principle for a functioning quality management system. Of those surveyed organisations that answered "yes" $21 \%$ and "mostly yes" $43 \%$ of organizations answered that managers are perceived as authoritative and an example in attitudes and behaviour. The largest number of answers "yes", which means a clear perception of managers as an example were in organisations with certificate according to standards AQAP ("yes" 43\% "mostly yes" 29\%), for at least with certificate TS 16949 ("yes" 15\%"mostly yes" 49\%).

Organizations with an established quality management system tend to review the mission, vision and values of the announced changes, respectively emerging changes. In terms of dynamic development and turbulent changes within the current globalized world, such an approach is insufficient. Strategic management is directed into the future and focuses on a long-term perspective. From this perspective, it is necessary to regularly review compliance and deal with set goals and aspirations with the requirements of the environment. Currently, the organization and management could not wait for change, but they have to encourage and incite them if they want to compete. Experience of successful enterprises points to the need to be a step forward. (Paulova, et al, 2010)

\section{REFERENCES}

Zgodavová, K. (2002): Factors of Intensive Product and Service Quality Improvement, Journal of Economics, Volume 50/No. 6/2002, ISSN 0013-3035

Paulová, I., et al. (2010): Perspectives of quality management development in relation with requirements of market in Slovak republic, AlumniPress, 2010, ISBN 978-80-8096039-1, Trnava

ISO 9001:2008, Quality Management Systems - Requirements ISO TS 16949 Quality management systems - Particular requirements for the application of ISO 9001:2000 for automotive production and relevant service part organizations 